\title{
La comunidad que viene: un programa del hombre por-venir en Giorgio Agamben
}

The Coming Community: A Program of the Coming Man in Giorgio Agamben

Emmanuel Taub

Universidad de Buenos Aires (Argentina)

Recibido: 2015-02-12

Enviado a pares: 2015-03-02

Aprobado por pares: 2015-05-30

Aprobado: 2015-06-13

Pensamiento y Cultura | ISSN: 0123-0999 | elSSN: 2027-5331

pensam.cult | Vol. 18-2 | Diciembre de 2015 | pp. 95-110

DOI: 10.5294/pecu.2015.18.2.5

\section{Para citar este artículo/To reference this article}

Taub, Emmanuel. 2015. “La comunidad que viene: un programa del hombre por-venir en Giorgio Agamben”, Pensamiento y Cultura 18 (2): 95: 110.

DOI: 10.5294/pecu.2015.18.2.5 


\section{La comunidad que viene: un programa del hombre por-venir en Giorgio Agamben}

Resumen: lo judío ha estado presente en la obra de Giorgio Agamben desde sus primeros trabajos hasta los últimos, especialmente a lo largo de su gran proyecto filosófico Homo sacer. Pocos pensadores de la segunda mitad del siglo XX como el filósofo italiano han hecho del judaísmo una parte del debate filosófico y político moderno, actualizando y reflexionando desde la particularidad de los conceptos hasta los avatares históricos de la historia del pueblo judío. El objetivo de este artículo es presentar una nueva lectura de su libro La comunità che viene, en donde creemos que se construye su programa para un hombre por-venir; y en donde la particularidad de la matriz judía se conforma como uno de los canales ocultos hacia "otro pensamiento" en el tiempo futuro.

Palabras clave: Giorgio Agamben; por-venir; comunidad; Homo sacer; judaísmo.

\section{The Coming Community: A Program of the Coming Man in Giorgio Agamben}

Abstract:Judaism has been present in Giorgio Agamben's entire work, particularly in his great philosophical project, Homo sacer. Few thinkers from the second half of the twentieth century, such as the Italian philosopher, have incorporated Judaism into the modern philosophical and political debate, updating it and reflecting from the particularity of the concepts to the vicissitudes of the Jewish people's history. The purpose of this paper is to offer a new reading of his book, La comunità, from where we believe his program for a 'coming man' is built, and where the particularity of the Jewish matrix becomes one of the hidden channels to "other thoughts" in the future.

Keywords: Giorgio Agamben; coming; community; Homo sacer; judaism. 


\section{Palabras preliminares}

La hipótesis de la que partimos en este trabajo es que La comunidad que viene de Giorgio Agamben es uno de sus libros "más judíos”, entendiendo esta expresión en el sentido de que es en donde podemos encontrar de una manera explícita elementos de la tradición y pensamiento judío que marcan el camino de sus indagaciones y reflexiones filosóficas.

En principio, podemos formular esta hipótesis desde las siguientes perspectivas: en primer lugar desde el tema principal del libro: aquí encontraremos la propuesta (o programa) de mayor densidad mesiánica, a diferencia de lo que uno puede creer que ha significado para su obra un libro como El tiempo que resta. Comentario a la carta de los romanos (Agamben 2006). En segundo lugar, a partir del programa mismo que se extiende a través de este pequeño, pero profundísimo, libro: no solo por el sentido que le da a lo "ejemplar" (que luego mutará a lo "paradigmático" o a la figura del "paradigma" en Signatura rerum. Sobre el método - Agamben 2008-), sino también por la forma de "programa" propositivo sobre una política por-venir. Allí pueden identificarse diferentes puntos de contacto con Sobre el programa de la filosofía venidera de Walter Benjamin. Si, como Benjamin señala en su programa,

la tarea de la futura teoría del conocimiento, en lo que hace al conocimiento, es encontrar la esfera de total neutralidad en relación a los conceptos de objeto y sujeto; o, en otras palabras: buscar la esfera autónoma propia del conocimiento en que este concepto ya no se refiera en modo alguno a la relación entre dos entidades metafísicas (Benjamin 2007, 157)

Entonces, la respuesta agambeniana a la búsqueda de la esfera de total neutralidad será la figura del "cualsea"; y desde allí elaborará su punto de partida.

En tercer y último lugar, por el método: en este libro, Agamben se emparenta con el "comentario" como método de construcción de saber, de la misma manera que este método constituye la base del pensamiento judío. Este método se ve reflejado igualmente en otros libros paralelos 
de Agamben: libros no menos complementarios y fundamentales para la comprensión del proyecto que conforman las obras Homo sacer.

En el pensamiento judío, desde la tradición rabínica o desde las diferentes corrientes del pensamiento judío moderno iniciado con la Haskalá (el Iluminismo judío), toda lectura es una excusa y también un comentario. ${ }^{1}$ Así se construye esta tradición de pensamiento: reflexionando y comentando las fuentes provenientes del texto bíblico como el camino para pensar el mundo, al hombre y la relación con Dios. Ésta es la forma de construir la historia y el conocimiento.

\section{Programa para un hombre por-venir}

Debemos partir diciendo que para el desarrollo de nuestro trabajo propondremos una lectura dialógica entre la propuesta agambeniana de La comunidad que viene y el pensamiento judío. Extendiendo así la reflexión a través del comentario y la exégesis de la obra de Agamben, y tomando como centro una de las partes más ricas en densidad filosófica de este libro: a saber, las últimas tesis sobre "lo irreparable". Estas tesis agambenianas se encuentran en diálogo, como él mismo indica, con el parágrafo $\$ 9$ de Ser y tiempo de Martin Heidegger y la proposición 6.44 del Tractatus wittgensteiniano.

Es importante hacer notar, primero, lo interesante de la proposición con la que se plantea el diálogo con Wittgenstein; ésta refiere a la idea de "mística", esto es, de lo más allá del mundo y del lenguaje. Escribe Wittgenstein: “6.44: No cómo sea el mundo es lo místico, sino que sea” (Wittgenstein 2010, 135). Y escribirá a continuación, en la proposición 6.45, que "el sentimiento del mundo como todo limitado es lo místico" (Wittgenstein 2010, 135). Aquí se nos indica que el misticismo habita en ese más allá de los límites, y que por ello crea la sensación —en el hombre- de un aprisionamiento de lo inexplicable e incognoscible cuando nos preguntamos por ello.

Podemos decir que elevar la pregunta por la mística aprieta - en el mismo movimiento- el nudo de la soga que está en el cuello de la razón. La mística es la salida de los límites del mundo que -como

1 Sobre la Torá y la Haskalá cfr. Stemberger 2011; sobre la Haskalá cfr. Baron 1965 y Baron 1968. 
veremos- Agamben busca traducir como parte de un mundo irreparable. La mística (entendida como la relación entre el hombre y el silencio de $\operatorname{Dios}^{2}$ ) es lo que representa lo irreparable y, a la vez, lo intermediario; lo más allá y más acá, traducido como un estar-entre-medio.

Segundo, en cuanto al parágrafo $\$ 9$ de Heidegger, ${ }^{3}$ se refiere a “aquel apriori que tiene que ser visible si la pregunta 'qué es el hombre' ha de poder ser filosóficamente dilucidada” (Heidegger 2005, 70).

El proyecto que extiende Agamben a lo largo de La comunidad que viene -y que como sugerimos aquí, constituye la "Urzelle", o "célula originaria", de muchas de sus futuras indagaciones - trata no solo sobre la relación entre la esfera de lo divino con lo humano, y del conocimiento filosófico y el conocimiento teológico, sino de un proyecto propositivo sobre una forma-de-vida posible para un mundo que, desde su origen, ha nacido en ruinas. En este sentido, no construimos el saber sobre las ruinas del mundo a través del ángel benjaminiano que mira de espaldas lo que deja atrás mientras avanza, sino sobre las ruinas que siempre han estado y que estarán ahí.

Agamben plantea un recorrido filosófico que se inicia en la figura del "cualsea" ["qualunque"], que es caracterizado como una "singularidad pura" entre la "cosa y la idea" que constituye un "afuera" (Agamben 2006, 57-58 ${ }^{4}$ hacia lo irreparable del mundo y de la existencia. Entre medio de estos dos polos, la figura de Dios se devela como el parámetro para construir una ética más allá del hombre que, en la figura del "reino mesiánico", hará un "pequeño desplazamiento", permitiendo que esa singularidad no-singular que es el cualsea se transforme en una espacialidad; en lo que Agamben llama los "lugares cualsea". ¿Qué es eso? Lo que se extiende ejemplarmente entre "cosa e idea", "nombre y nominación”, "lenguaje y sentido" (Agamben 2006, 57).

2 Cfr. Scholem 2000.

3 Este parágrafo es el eje sobre el cual estará dialogando Agamben. En este diálogo reposiciona todo lo expuesto en La comunidad que viene (y de ahí la riqueza de estas tesis finales) ubicando el libro, indefectiblemente, como un tratado filosófico de un fuerte peso político en cuanto a las figuras dialogantes y su búsqueda.

4 Es importante remarcar aquí que utilizamos aquí la traducción al español del libro de Agamben cotejando, sin embargo, la misma con la versión original italiana (Agamben 2001). Si modificamos la traducción será indicado en una nota. 
Pero, ¿qué es lo irreparable? O más aún: si existe lo irreparable, ¿qué se ha roto y qué debe repararse? Lo roto es Dios. Solamente una divinidad que se ha quebrado puede develarse como creadora, puede crear. En palabras de Agamben, "el mundo - en cuanto absoluta, irreparablemente profano- es Dios" (Agamben 2006, 76). Digamos entonces nosotros que si Dios es lo roto la idea de Creación es, desde su propia concepción, irreparable; de la misma forma que la Revelación carga consigo la huella de esa ruptura y de la negatividad como fuerza constitutiva. Desde la perspectiva trazada por Agamben, esto es el sentido de la revelación; por eso, escribe, "no significa revelación de la sacralidad del mundo, sino solo revelación de su carácter irreparablemente profano. [...] La revelación entrega el mundo a la profanación y a la coseidad" (Agamben 2006, 75). Podemos agregar que es por ello que este sentido de negatividad como fuerza constitutiva se revela y crea, pero que no debe ser entendida (esta negatividad) como algo negativo, sino como la im-posibilidad de completud, como lo in-completo que llevamos desde la constitución del mundo, del hombre o de la ley, y que se vuelve en una tarea (im-posible) por completar. Por su parte, Agamben escribirá:

Lo irreparable es que las cosas sean como son [...] asignadas sin remedio a su manera de ser. Irreparables son los estados de cosas, tal como ellos son: tristes o ligeros, atroces o felices. Como el mundo es, como tú eres, esto es lo Irreparable (Agamben 2006, 75).

Al considerar éste como el piso desde donde partir, sabremos del carácter irreparable del mundo y de lo creado y, por esa razón, podremos encontrar "la raíz de toda alegría y de todo dolor puros". Como escribe Agamben, "el mundo es así como es" (Agamben 2006: 76). En este sentido, y retomando (o completando) los postulados de Wittgenstein, dirá Agamben que "lo que cambian no son las cosas, sino sus límites. Es como si sobre ellas estuviese ahora suspendida algo así como una aureola, una gloria" (Agamben 2006, 77); haciendo que el ser - retomando seguidamente los postulados heideggerianos- siempre se da en la modalidad, o sea, que "...es sus modalidades. No es así, sino que es 
ese su así" (Agamben 2006, 77). Este "así", para nuestros postulados, está representado por la negatividad constitutiva con los prefijos "im-" o "in-". Para Agamben, caracteriza el "no de otra manera" (Agamben $2006,79)$ que es el "único modo correcto de entender la teología negativa: ni esto ni aquello, ni así ni así, sino así como es, con todos sus predicados" (Agamben 2006, 79-80). Por eso amplía diciendo: "No de otra manera niega cada predicado como propiedad [...] pero los retoma a todos como im-propiedad" (Agamben 2006, 81). Esta "im-propiedad" que plantea Agamben se emparentará con nuestra "im-posibilidad" o "in-utilidad", como constitutivas de la potencia Divina en su relación con el hombre y el mundo.

Pero no prosigamos sin retomar brevemente esta "aureola" que Agamben caracterizó como lo "que simplemente se añade a la perfección -algo así como un estremecerse de lo que es perfecto, apenas un irisarse sus límites" (Agamben 2006, 48). ¿Qué quiere decir esto? Este sentido "áurico" es como "un pequeño desplazamiento" que hace de lo que creemos algo diferente pero sin perder la semejanza.

Esta idea es tomada por Agamben de una parábola rabínica del reino mesiánico que Benjamin había escuchado por boca de Scholem, en la que lo por-venir "será justamente como aquí. [...] Todo será como ahora, solo que un poco diverso" (Agamben 2006, 47). La importancia está en ese "poco diverso", en ese "pequeño desplazamiento", en esa no necesidad de destruir todo para volver a construirlo nuevamente, sino en mover un poco la existencia.

En cuanto a la tradición judía, recordemos brevemente que después del diluvio Dios, promete no volver a destruir lo creado y que este pacto se trasladará en el devenir del tiempo a todos los patriarcas y profetas. De la misma forma, digamos que la base del mesianismo judío está proyectada como un tiempo en este mundo y en esta tierra, no en otro reino. El mesianismo judío será aquí. ${ }^{6}$

Pero Agamben prosigue con su planteo y dice que si "existir" significa "cualificarse" por someterse al "tormento de ser cual" — razón por

5 Cfr. Agamben 2006: 55.

6 Cfr. Taub 2013. 
la que "cada ser es y ha de ser su modo de ser, su manera manantial: ser tal cual es" (Agamben 2006, 83) -, entonces el "tal" le da lugar al "cual", exponiéndolo, sacándolo a la luz; el lenguaje deja entrar al "como" para "decir algo como algo" (Agamben 2006, 83). El "como" es el puente entre lo dicho y lo expuesto, es - en palabras de Agamben- "la relación de exposición", y por eso se tiene que volver el tema de la filosofía. Por eso escribe Agamben: "Este como originario es el tema de la filosofía, el asunto del pensamiento" (Agamben 2006, 84).

El "como" es la característica del "juicio", es la relación "sujeto-objeto" - como bien retoma Agamben de los postulados de Heidegger-. Sin embargo, explica Agamben, el "como" se vuelve un camino sin salida, una "pura exterioridad" ya que solo muestra "algo como algo". Es por ello que se debe introducir un tercer término: "la cosa misma, el ser tal cual, que no es ni lo denotado ni el sentido" (Agamben 2006, 84). El "ser-tal de cada cosa es la idea", una existencia paradigmática que aparece al lado de cada cosa, que se le añade mostrándose a sí misma y caracterizando a la cosa misma. Esto es en lo que ha devenido la idea de "aureola", dice Agamben, porque la idea es entonces "una tal-cualidad eterna" (Agamben 2006, 85).

Entre la Revelación y lo Irreparable, entre la tarea de la filosofía y la "tal-cualidad" del cualsea, aparece para Agamben la idea (imposible) de la Redención. Para la tradición judía existe una relación entre Dios, el hombre y el mundo: Dios Creador, Revelador y Redentor. Para Agamben, por su parte, la redención no es solamente el por-venir de la Revelación, o sea el acto de correlación de lo dado como devuelto, sino la consumación de lo irreparable como límite posible y como más allá. La redención, dice Agamben, "es la pérdida irreparable de lo perdido, la definitiva profanidad de lo profano. Pero justo por eso, aquéllos tocan ahora su límite: un límite adviene" (Agamben 2006, 87).

Solo al sabernos habitantes de lo irreparable, de lo sin remedio, podemos construir un sentido de "esperanza"; que las cosas estén "así y asi" dice Agamben, permite desaferrarnos de la coseidad del mundo y de la existencia (Agamben 2006: 87). Por ello este "perderse de las cosas" constituye la posibilidad de vislumbrar un límite y exponerse a éste, no ya desde el maniqueísmo de lo que "es o no es", sino permitiendo la entrada 
de un tercer término -cualsea, intermediario, ejemplar, podríamos decir-que es el "más bien" (Agamben 2006, 89).

El término "más bien" nos permite "poder negar el no-ser" o, como escribe Agamben, "La maravilla no es que algo haya podido ser, sino que haya podido negar el no-ser" (Agamben 2006, 89). El “más bien” es la "potencia”. Por eso, escribe el filósofo italiano, existimos "más bien" que la nada, ese es el territorio del lenguaje que nos abre al ser y a la existencia. La potencia del hombre no está dada en ser o no ser, sino en poder negar el no-ser. Dicho de otro modo: el ser humano es el animal que puede negarse a sí mismo y a su existencia, que puede negar la vida, y en la potencia de esa negación se halla la responsabilidad por la existencia. La responsabilidad por saberse parte de un mundo irreparable y trascendente más allá del hombre.

Si el pilar del judaísmo ante la vida dice, en las palabras de Moisés, "Hoy mismo convoco como testigos al cielo y a la tierra, de que ponga ante ti la vida y la muerte, la bendición y la maldición. Elige la vida [“bajarta ba-jaim"], para que vivas tú y tu descendencia” (Deut. 30, 19), Agamben nos dirá que el amor es poder ver "algo en su ser-ahí", lo irreparable (ni necesario ni contingente, sino simplemente irreparable). Porque "en el punto en el que se percibe la irreparabilidad del mundo - escribe Agamben - en aquel punto éste es trascendente" (Agamben 2006, 90).

\section{El cualsea y el sentido común rosenzweigiano}

Proponemos retomar ahora, desde el pensamiento judío, la idea del "sentido común" de Franz Rosenzweig con el propósito de pensar en la idea de la comunidad de saber como proyecto por-venir; en donde el "cualsea" agambeniano pueda alcanzar la plenitud como forma-de-vida.

Para ello, es necesario que recordemos el postulado de Rosenzweig: la idea del "sentido común" aparece expresada en el contexto de los debates que en los años veinte mantuvo Martin Buber en torno a la ley judía, y en lo que formará parte de sus textos sobre educación. ${ }^{7}$ Específicamente, lo encontramos desarrollado en "Los constructores. Acerca de la ley", de 1924 (Rosenzweig 2007). 
Ante el sentido de la ley y la vida judía, Rosenzweig dirá que la ley debe ser "aprendida y vivida, aprendida y cantada, todos los días y el día de la muerte" (Rosenzweig 2007: 275-276); o sea, que el sentido más íntimo de la ley judía es que siempre es capaz de convertirse en una forma de vida, y ello es posible porque lo que existe es un vínculo constitutivo entre la ley y la acción (tanto como normatividad y como temporalidad). Es el salto final desde lo que conozco a lo que tengo que conocer, y ese salto es la enseñanza judía, la cual es una realidad para el pueblo judío (Rosenzweig 2007, 278).

Rosenzweig emparenta el nacimiento del pueblo con su destino, al decir que "el pueblo no ha surgido, sino que fue extraído de en medio de otro pueblo (Deuteronomio 4, 34)"; es decir, la interpretación de lo sido en el presente solo puede pertenecer al pueblo para quien recuerda su origen en un movimiento que lo atraviesa y toma sentido al proyectarlo como tiempo futuro, como forma de vida. Es así que dice que "el aprendizaje de lo cognoscible es la condición indispensable para que la enseñanza de lo desconocido se convierta en su enseñanza" (Rosenzweig 2007, 289).

Su propuesta gira en torno a reemplazar lo prohibido (el dogmatismo de la ortodoxia) por algo positivo, ya que "lo permitido" —dice - tiene en sí mismo una negación originaria, lo que se puede y lo que no. Pero en la ley no debe haber un "permitido" de entrada (de hecho), sino la costumbre y el sentido, su interpretación. Esto es lo que conforma el "judaísmo vivo": para que sea posible, Rosenzweig escribe, "la costumbre y el sentido tienen que tener siempre el mismo rango y la misma constancia que tiene la ley" (Rosenzweig 2007, 280). La ley no debe ser aquello que castiga la acción realizada, sino el sentido común que conforma el sentido mismo de la acción antes de realizarse. De aquí nace la idea del "sentido común" que se vuelve requisito necesario para la acción de la vida judía y que caracterizará al mandamiento como proyección futura del devenir de cualquier tipo de ley o legislación: si esta equiparación ocurre, entonces la ley se vuelve acción y vida, participando de la positividad de la costumbre, volviéndose mandamiento. Así lo dice Rosenzweig: “... ya no es la prohibición que determina su carácter, sino el mandamiento" (Rosenzweig 2007, 281) el que vuelve a la ley en 
acción positiva: "La ley — continúa- debe volver a ser mandamiento, mandamiento que se vuelve acción inmediatamente en el instante que se lo escucha" (Rosenzweig 2007, 282).

Esta es la base de la propuesta del pensador judío: al volver la ley en mandamiento, ésta se apropia no de la consecuencia de una prohibición, sino del sentido de la acción o de la forma de vida. Sobre esto debe estar sostenida la vida judía y el sentido de lo común.

Saber no es lo mismo que ser sabio. De la misma manera, lo factible por sí solo no es acción. Para ello se necesita un "salto" desde donde surge la acción, dice Rosenzweig: "allí donde la voz del mandamiento, de modo instantáneo, hace que las chispas salten del 'yo debo' hacia el 'yo puedo'. A partir de esos mandamientos, y solo a partir de estos, se construye la ley" (Rosenzweig 2007, 283). Digamos entonces que la forma-de-vida de la comunidad cualsea no puede estar configurada desde el parámetro del Estado de derecho, sino desde la comunidad misma como entidad viva, en donde la soberanía de la norma desplace la dictadura de la ley.

La comunidad que viene es el proyecto teológico-político para un mundo, o una existencia, irreparable: "la vida que comienza en la tierra tras el último día” - dice Agamben - "la vida humana" (Agamben 2006, 14). ¿Qué forma de gobierno puede proyectar el hombre ante el escenario de su irreparabilidad? O, en palabras de Agamben,

¿Cuál puede ser la política de la singularidad cualsea, esto es, de un ser cuya comunidad no está medida por condición alguna de pertenencia (el ser rojo, italiano, comunista) ni por la simple ausencia de condiciones [...], sino por la pertenencia misma? (Agamben 2006, 69).

La respuesta que esboza Agamben, y que mucho se vincula a la forma teológico-política judía por antonomasia (la kehilá), es la comunidad. La forma de vida cualsea, en el territorio de lo existente y lo que será, de lo pronunciable y de lo imposible de imaginar, entre "la cosa idea y la idea", "el nombre y el nominar", "el lenguaje y el sentido". La comunidad (que luego la veremos encarnada en textos como Altissima 
povertà o $L^{\prime}$ uso dei corpi $i^{8}$ ) es la forma política caracterizada por otra forma de política: la amistad'; $y$, por otro lado, es la forma de gobierno que se encuentra en la intersección de lo teológico y lo político, pero ya no del lado de la institución y la figura de Dios, o sea, del devenir del Estado, sino desde los hombres.

La comunidad es lo que Agamben llama el ejemplo: "un concepto que escapa de la antinomia entre lo universal y el particular y que resulta siempre familiar" (Agamben 2006, 15). La comunidad cualsea es el ejemplo por antonomasia: allí todo se despliega al mismo tiempo como "inclasificable e imprescindible" (Agamben 2006, 16). La comunidad cualsea es la comunidad del hombre por-venir o, dicho de otro modo: la comunidad cualsea es la comunidad por-venir, en donde lo irreparable se vuelve ese espacio entre lo divino y lo mundano, entre lo realizado y lo irrealizable, entre lo dicho y lo nunca por decir. Allí el hombre, o el "resto" de todos los pueblos, podrá encontrar su hogar. Así lo escribe Agamben, "serán los primeros ciudadanos de una comunidad sin presupuestos ni Estado, en la que el poder anulador y destinante de lo común será pacificado, y la Shejiná habrá cesado de beber la leche maligna de la propia separación" (Agamben 2006, 68).

¿Qué quiere decir Agamben con este uso de la idea de la shejiná develada? Quiere decir que la palabra divina, como manifestación de lo divino en la tierra, se devele como autónoma, y en ese develamiento quite el velo del secreto de la creación, de la esencia de toda cosa y toda palabra. Esto posibilita, según los cabalistas - a quienes relee Agamben - , tornarse en una fuerza maléfica. Pues, quien controla con la palabra el secreto de las cosas, controla también la posibilidad de crear y la potencia del lenguaje; lo que según Agamben, por otro lado, caracteriza nuestro tiempo actual (Agamben 2006, 67-68).

\footnotetext{
8 Cfr. Agamben 2011; Agamben 2014a.

9 Recordemos en este sentido su texto fundamental sobre la amistad publicado en la compilación ¿Qué es un dispositivo?. Cfr. Agamben 2014b.
} 


\section{Propuesta final}

Nuestra propuesta es pensar al "cualsea" agambeniano - a esta singularidad "amable", esta "inteligencia de una inteligibilidad" (Agamben 2006, 12)—, junto al sentido in-útil de la comunidad de saber. Y, en este encuentro, tornándose ambas paradojas de la Modernidad (y del mundo judío).

En su sentido paradójico se dan como una herida siempre abierta para el mundo del capital, de la velocidad y de las conexiones. Una herida dada por el sentido de in-utilidad o de la vida cualsea, en donde la forma de vida está consagrada a la pérdida del tiempo como consagración a tareas (inútiles) como la lectura, la música, la escritura o la filosofía (lo que en las palabras proféticas de Paul Valéry son las "obras del espíritu").

Perder el tiempo se convierte así en un arma contra la hípermundanidad del tiempo moderno: haciendo del tiempo algo que debe pasar y no lo que marca el ritmo de nuestros cuerpos útiles, para romper de esa manera con la mercantilización del tiempo. Es por ello necesario re-crear (porque no podemos tomarlos linealmente como un "regreso") el sentido de la escuela de estudio o la comunidad de saber, teológica y filosófica. Llevando adelante la vida in-útil de quienes se consagran a la comunidad de saber, es posible hacer del "cualsea" y del "sentido común" una forma de vida posible, un programa para el hombre por-venir.

Construimos así el nuevo, o posible, flâneur ya esbozado por Baudelaire y teorizado por Walter Benjamin. Sin embargo, este "paseante" ya no solo estará caracterizado por el caminar o el deambular como forma de perder el tiempo, sino en la pérdida de tiempo o in-utilidad como responsabilidad ante la configuración de una forma de mundo. Es ahí en donde es posible que se despliegue lo que Agamben ha llamado la "ética" en La comunidad que viene: una potencia en sí misma más allá del hombre como "esencia", como "vocación histórica o espiritual", o como "destino biológico” (Agamben 2006, 41), como lo más allá del hombre y al mismo tiempo como horizonte de posibilidad ante la irreparabilidad del mundo.

La revolución posible es aquella que se halla sostenida desde el "no". Entendiéndolo como "imposibilidad" — no como negación-, como "irreparabilidad". Por eso la comunidad que viene debe ser pensada 
desde la in-acción como fundamento paradójico o "ejemplar" del mundo de la acción y de la vida activa. Pero ya no desde la vita activa arendtiana - que vincula la acción con lo político—, sino desde la "vida in-útil", que une la comunidad con la irreparabilidad del ser humano. ${ }^{10}$

La manera de enfrentar la configuración moderna es desde adentro, desde la inoperancia del ser humano moderno ante su modernidad: esta es la tarea, y la característica del cualsea. Escribe Agamben:

no se trata de apatía, ni de promiscuidad, ni de resignación. Estas singularidades, sin embargo, comunican solo en el espacio vacío del ejemplo, sin estar ligadas por propiedad alguna común, por identidad alguna. Están expropiadas de toda identidad para apropiarse de la pertenencia misma, del signo e... (Agamben 2006, 16).

Desde la perspectiva del pensamiento judío, esto mismo está dado ya no como un revelarse, sino como una consagración. El ejemplo tal vez más acabado de esta figura está dada por el shabat (no como la consagración semanal luego de la tarea cotidiana, de la acción, o de la creación, sino) como una forma de vida extendida a toda la comunidad por-venir. El shabat es tal vez la práctica más revolucionaria que ha dado el judaísmo en el tiempo y en el espacio: una reconfiguración de las dos dimensiones como estudio e in-acción, como no utilidad. Lo que en palabras de Giorgio Agamben es llamado “inoperatividad" (Agamben 2006, 94), es la forma de no hacer del tiempo y el espacio el territorio de la vida útil y de la mercancía, de la historia de los medios de producción. El shabat convierte la negatividad de lo no-útil o in-útil en la consagración al estudio, al hombre como plenitud, y al mundo como lo creado.

Este sentido es retomado por Agamben en la "Apostilla de 2001" a la que llama "Tiqquun de la noche". Allí escribe que la característica del tiempo de la comunidad que viene es el sentido de una "generali-

10 La acción para Hannah Arendt es una de las tres actividades fundamentales de la vita activa, pero también al ser la única actividad que se da entre los hombres "sin mediación de cosas o materia, corresponde a la condición humana de la pluralidad" (Arendt 2013, 2122). Esta condición de pluralidad es la condición, "conditio per quam", de toda vida política (Arendt 2013, 22). 
zación sin precedentes de la condición mesiánica", donde el "resto" de los hombres estará consagrado a un tiempo marcado por "la ausencia de obra, la singularidad cualsea, el bloom" (Agamben 2006, 94). Y en este contexto, "el paradigma de la política que viene" - escribe- no es el trabajo, sino la "inoperatividad y descreación” (Agamben 2006, 94). Esta es la vocación sabática que caracteriza el shabat: la abstención de realizar toda acción productiva para dedicarse a la in-acción o a la tarea inútil, porque ahí, escribe Agamben, "la vida sin forma y las formas sin vida coinciden en una forma de vida" (Agamben 2006, 94).

El sabbat, entonces, no es un tiempo de no trabajo, sino de diferencia o separación con nuestro tiempo/espacio cotidiano. Hace del tiempo del consumo y de la utilidad cotidiana un tiempo sin medida; un tiempo de "otra medida" determinada por la in-utilidad del estudio, la lectura y la consagración al hombre en su vínculo con el mundo y lo divino. En una palabra, con la shejiná, con la divina presencia profanada o, mejor dicho, secularizada, con la palabra por crear.

\section{Bibliografía}

Agamben, Giorgio. Altissima Povertà: Regole Monastiche e forma di vita. Homo sacer, IV, 1. Vicenza: Neri Pozza Editore. 2011.

Agamben, Giorgio. Il tempo che resta: Un commento alla Lettera ai romani. Torino: Bollati Boringhieri. 2000.

Agamben, Giorgio. La comunità che viene. Torino: Bollati Boringhieri. 2001.

Agamben, Giorgio. La Comunidad que Viene. trad. José Luis Villacañas, Claudia La Rocca y Ester Quirós. Valencia: Pre-Textos. 2006.

Agamben, Giorgio. L'uso dei Corpi. Homo sacer, IV, 2. Vicenza: Neri Pozza Editore. 2014a.

Agamben, Giorgio. Signatura rerum: Sul método. Torino: Bollati Boringhieri. 2008.

Agamben, Giorgio. ¿Qué es un Dispositivo? El Amigo. La Iglesia y el Reino. trad. Mercedes Ruvituso. Buenos Aires: Adriana Hidalgo editora. 2014b. 
Arendt, Hannah. La Condición Humana. trad. Ramón Gil Novales. Buenos Aires: Paidós. 2013.

Baron, Salo Wittmayer. Grandes Épocas e Ideas del Pueblo Judío. VI: La Época Moderna. trad. Matilde Horne. Buenos Aires: Paidós. 1965.

Baron, Salo Wittmayer. Historia Social y Religiosa del Pueblo Judío. VIII: Filosofía y ciencia. trad. Eduardo Goligorsky. Buenos Aires: Paidós. 1968.

Benjamin, Walter. "Sobre el Programa de la Filosofía Venidera", en Benjamin, Walter. Obras. Libro II / vol. 1. trad. Jorge Navarro Pérez. Madrid: Abada. 2007.

Heidegger, Martin. Ser y Tiempo. trad. Jorge Eduardo Rivera. Santiago de Chile: Editorial Universitaria. 2005.

Rosenzweig, Franz. On Jewish learning. Edited by N.N. Glatzer. Wisconsin: The University of Wisconsin Press. 1995.

Rosenzweig, Franz. Lo Humano, lo Divino y lo Mundano: Escritos. Edición y trad. Marcelo G. Burello. Buenos Aires: Lilmod, 2007.

Scholem, Gershom. Las Grandes Tendencias de la Mística Judía. trad. Beatriz Oberländer. Madrid: Siruela. 2000.

Stemberger, Günter. El Judaísmo Clásico: Cultura e HISTORIA del Periodo Rabínico. trad. Lorena Miralles Maciá. Madrid: Trotta. 2011. Taub, Emmanuel. Mesianismo y Redención: Prolegómenos para una Teología Política Judía. Buenos Aires-Madrid: Miño y Dávila. 2013. Wittgenstein, Ludwig. Tractatus Lógico-Philosophicus (edición bilingüe), en Wittgenstein, Ludwig. Wittgenstein I. trad. Jacobo Muñoz e Isidoro Reguera. Madrid: Gredos. 2010. 